Research Article

\title{
Preparation and Properties of RDX/Aluminum Composites by Spray-Drying Method
}

\author{
Hongyan Sun, Xiaodong Li ${ }^{\mathbb{D}}$, Pengfei Wu, Changgui Song, and Yue Yang \\ School of Environment and Safety Engineering, North University of China, Taiyuan 030051, China \\ Correspondence should be addressed to Xiaodong Li; lixd78@126.com
}

Received 29 June 2020; Revised 19 August 2020; Accepted 15 October 2020; Published 4 November 2020

Academic Editor: Giuseppe Compagnini

Copyright (C) 2020 Hongyan Sun et al. This is an open access article distributed under the Creative Commons Attribution License, which permits unrestricted use, distribution, and reproduction in any medium, provided the original work is properly cited.

\begin{abstract}
$\mathrm{RDX} /$ aluminum composites were prepared by the spray-drying method with $\mathrm{F}_{2602}$ as a binder. The morphology and covering effect of composites were characterized by scanning electron microscopy (SEM) and X-ray photoelectron spectroscopy (XPS). The effect of the processing parameters on the morphology of the samples was investigated. The impact sensitivity and thermal decomposition behavior of RDX/aluminum composites were also measured and analyzed. Optimal morphology of samples was achieved when the inlet temperature, nitrogen flow rate, and suspension feed flow rates were $80^{\circ} \mathrm{C}, 473 \mathrm{~L} \cdot \mathrm{h}^{-1}$, and $4.5 \mathrm{~mL} \cdot \mathrm{min}^{-1}$, respectively. In addition, RDX/aluminum composites with the same content were prepared by a coverage-mixing method for comparative analysis. Experimental results showed that the thermal sensitivity and the impact sensitivity of RDX/aluminum composites prepared by the spray-drying method were significantly lower than those of RDX/aluminum composites prepared by the coverage-mixing method.
\end{abstract}

\section{Introduction}

The addition of metal powder with high heat value to explosive composition is a known method to improve their efficiency. And in particular, it also plays an important role in enhancing their blast effect and underwater performances [1-3], due to the reaction with the decomposition products of the explosive and environmental components [4]. Aluminized explosives, as a kind of metal-containing explosives in mixed explosives, have been widely used in various applications owing to its high density, explosion heat, and explosive capacity [5-8].

At present, many studies on preparation methods of aluminized explosive have been reported, such as the mechanical mixing method [9], direct method [10], sol-gel method [11], and others [12]. However, it is difficult to mix the aluminum particles and explosive particles evenly to obtain the aluminized explosives with excellent performance, due to the agglomeration of nanometer aluminum and the large particle size of the explosive. At the same time, the mixing uniformity of each component in aluminized explosives directly affects its charge density and detonation performance [13]. Therefore, in order to increase the energy release rate of the detonation reaction zone and the reaction completeness of aluminum powder, a composite with a larger contact surface area between the components and shorter reaction time was prepared [14].

Spray-drying can easily control the composition and particle size of a product. It has been extensively used in the preparation of energetic materials [15-17]. For instance, a kind of aluminum/HMX nanocomposite was prepared by Zhigach et al. [18] successfully with the spray-drying method, with the distribution of the components uniform.

In this study, the $\mathrm{RDX} / \mathrm{Al}$ composites were prepared by the spray-drying method successfully, and RDX in suspension was crystallized on nano-Al particles, which could reduce the agglomeration phenomenon. Furthermore, the morphology, crystal structure, surface element distribution, thermal decomposition, and impact sensitivity of $\mathrm{RDX} / \mathrm{Al}$ composites were analyzed and investigated for comparison with the physical mixtures. 


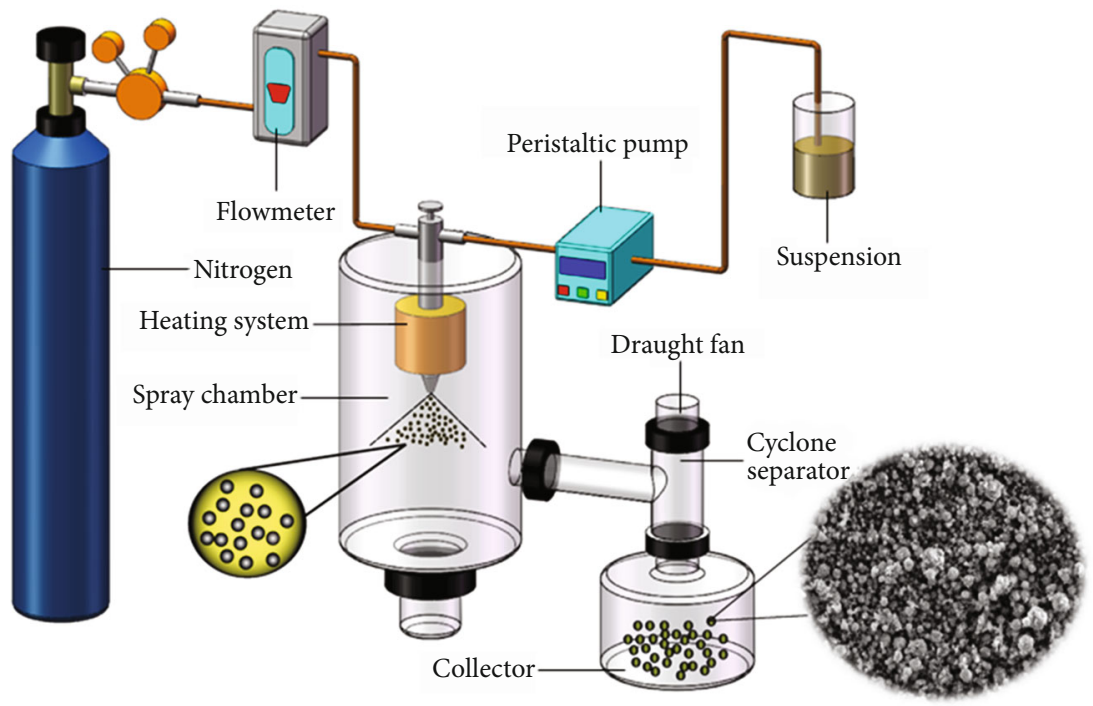

FIGURE 1: Flow chart of RDX/Al composites fabricated via spray-drying technique.

\section{Experimental Section}

2.1. Materials. RDX was provided by Gansu Yinguang Chemical Industry Ltd. nAl particles were obtained from Aladdin Industrial Co., China, with an average diameter of $\sim 150 \mathrm{~nm}$. Acetone, ethyl acetate, and dimethyl sulfoxide were purchased from Tianjin Tianda Chemical Industry Ltd. $\mathrm{F}_{2602}$ was obtained from Shanghai 3F New Chemical Materials Co., Ltd.

2.2. Preparation of RDX/Aluminum Composites. RDX/Al composites were obtained using two methods, the spraydrying method and the coverage-mixing method. The experimental procedures are as follows.

2.2.1. Spray-Drying Method. Figure 1 shows the flow chart of $\mathrm{RDX} / \mathrm{Al}$ composites fabricated via the spray-drying technique. Firstly, RDX and $\mathrm{F}_{2602}$ were dissolved into acetone to form a solution. And then, the $\mathrm{nAl}$ was added into the solution (the ratio of $\mathrm{RDX} / \mathrm{Al} / \mathrm{F} 2602$ was $63 / 35 / 2$ ), and the ratios of acetone to material are $99: 1$. With stirring and ultrasonic dispersing, the $\mathrm{nAl}$ was dispersed in the solution, and a stable suspension was obtained. Finally, the suspension was sprayed and dried to produce RDX/Al composites using a Mini Buchi 290 spray-dryer. The inlet temperature, nitrogen flow rate, and the feed rate of suspension were set at the desired values.

2.2.2. Coverage-Mixing Method. For the recrystallization of RDX, the raw RDX was dissolved in dimethyl sulfoxide to form a solution, and distilled water was added into a vessel. Then, the solution was added into the distilled water by an ultrasonic spray refining device. After filtering, washing, and freeze-drying, the recrystallized RDX was obtained.

For the RDX/Al composites, the preparation of RDX/Al composites was carried out as follows. $\mathrm{F}_{2602}$ was dissolved into ethyl acetate to form a solution first. Secondly, a certain proportion of the recrystallized RDX and Al was weighed and mixed evenly. Then, RDX/Al was added into the binder solu-
TABLE 1: Spray-drying process parameters.

\begin{tabular}{lccc}
\hline Process parameters & 1 & 2 & 3 \\
\hline Inlet temperature $\left({ }^{\circ} \mathrm{C}\right)$ & 60 & 70 & 80 \\
Nitrogen flow rate $\left(\mathrm{L} \cdot \mathrm{h}^{-1}\right)$ & 246 & 357 & 473 \\
Feed suspension flow rate $\left(\mathrm{mL} \cdot \mathrm{min}^{-1}\right)$ & 1.5 & 4.5 & 7.5 \\
\hline
\end{tabular}

tion. After the solvent volatilized, RDX/Al composites were obtained.

2.3. Characterization. The size and morphology of RDX/Al composites were observed by a scanning electron microscope (SEM, Tescan Mira3 LMH, Czech). X-ray diffraction (XRD, Dandong Haoyuan DX-2700, China) was used to investigate the crystal form of raw RDX, recrystallized RDX, $\mathrm{Al}$, and composites. The thermal decomposition behavior and the surface element distribution of the samples were studied by a differential scanning calorimeter (DSC, Yingnuo DSC800, China) and X-ray photoelectron spectroscopy (XPS, Ulvac-Phi PHI-5000, Japan). All samples were analyzed for impact sensitivity at room temperature using an HGZ-1 impact instrument according to the GJB772 A-1997 standard method [19]. The test conditions are the following: sample mass, $35 \mathrm{mg}$; drop weight, $2.50 \mathrm{~kg}$. The results were expressed by the critical drop height of $50 \%$ explosion probability $\left(H_{50}\right)$.

\section{Results and Discussion}

3.1. Influence of Processing Parameters on Sample Morphology. Spray-drying process parameters (inlet temperature, nitrogen flow rate, and feed suspension flow rate) have significant effects on the morphology of RDX/Al composite energetic materials. The experimental scheme is shown in Table 1. The morphology of samples prepared under different process parameters was compared and analyzed. 


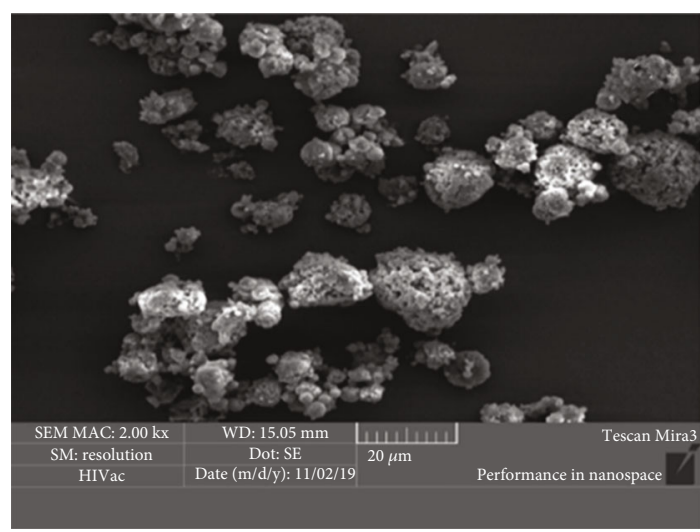

(a)

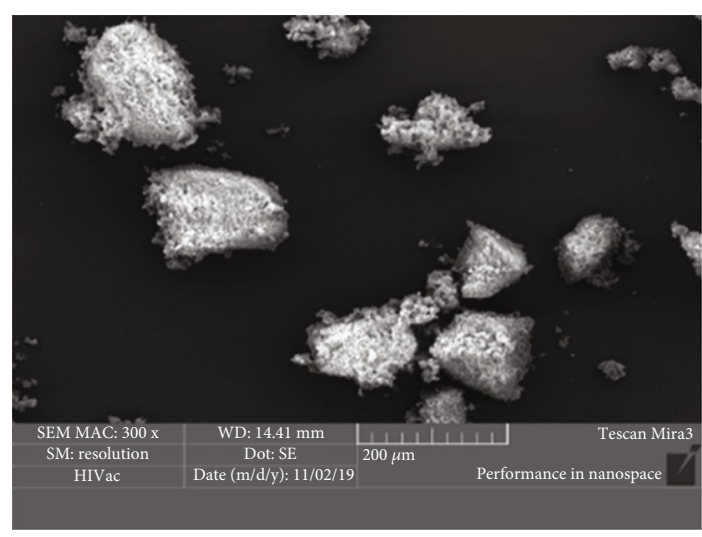

(b)

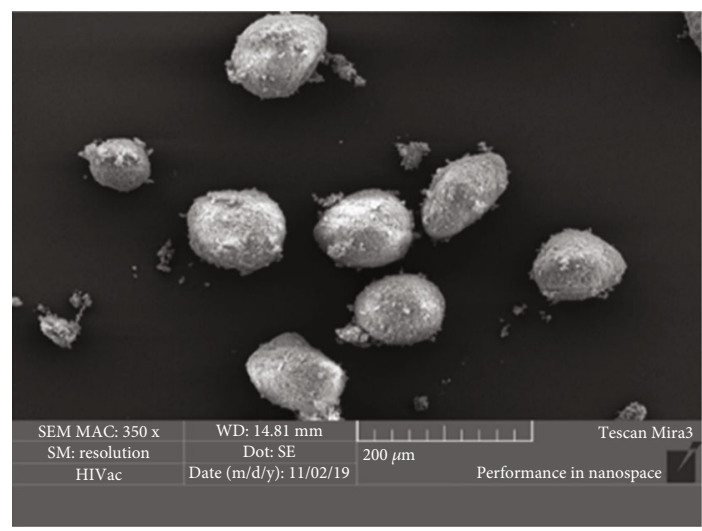

(c)

Figure 2: SEM images of samples under different nitrogen flow rates: (a) $246 \mathrm{~L} \cdot \mathrm{h}^{-1}$, (b) $357 \mathrm{~L} \cdot \mathrm{h}^{-1}$, and (c) $473 \mathrm{~L} \cdot \mathrm{h}^{-1}$.

3.1.1. Nitrogen Flow Rate. As is shown in Figure 2, three samples were prepared by spray-drying at different nitrogen flow rates $\left(246,357\right.$, and $\left.473 \mathrm{~L} \cdot \mathrm{h}^{-1}\right)$. The inlet temperature and feed suspension flow rate were chosen as $80^{\circ} \mathrm{C}$ and $4.5 \mathrm{~mL} \cdot \mathrm{min}^{-1}$, respectively. The particles produced at the nitrogen flow rate of $246 \mathrm{~L} \cdot \mathrm{h}^{-1}$ are irregular in shape and size. Figure 2(b) shows that the particles obtained at $357 \mathrm{~L} \cdot \mathrm{h}^{-1}$ are rough in surface and have many hollows on their surfaces. The particles obtained at $473 \mathrm{~L} \cdot \mathrm{h}^{-1}$ are spherical, and the size ranges from $100 \mu \mathrm{m}$ to $200 \mu \mathrm{m}$ (Figure 2(c)). The evaporation rate of the solvent in droplets is accelerated with the

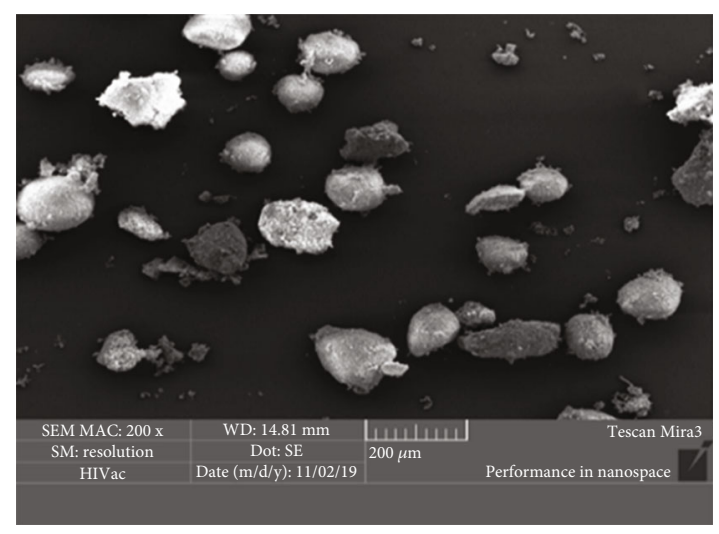

(a)

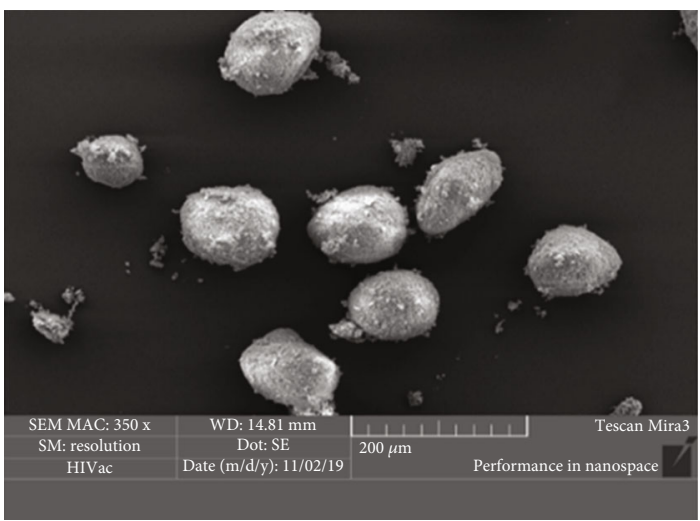

(b)

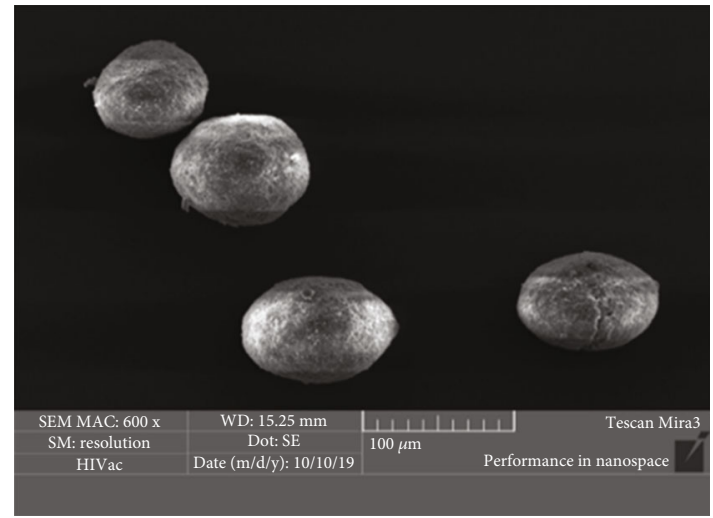

(c)

FIGURE 3: SEM images of samples under different inlet temperature: (a) $60^{\circ} \mathrm{C}$, (b) $70^{\circ} \mathrm{C}$, and (c) $80^{\circ} \mathrm{C}$.

increase of the nitrogen flow rate. When the vapor pressure formed by evaporation of the solvent inside the large droplets is greater than that of outside the sphere, the wet bulb shell will break. This caused the products to have irregular shapes [20]. So, the particle prepared by spray-drying at $473 \mathrm{~L} \cdot \mathrm{h}^{-1}$ was considered to be the optimum achievable.

3.1.2. Inlet Temperature. As shown in Figure 3, three samples were produced by spray-drying at a nitrogen flow rate of $473 \mathrm{~L} \cdot \mathrm{h}^{-1}$ and feed suspension flow rate of $4.5 \mathrm{~mL} \cdot \mathrm{min}^{-1}$. Figures 3(a) and 3(b) show that the particles obtained at $60^{\circ} \mathrm{C}$ and $70^{\circ} \mathrm{C}$ adhere to each other, with a rough surface. 
In Figure 3(c), however, the particles are spherical and the particle surface is smooth without any cracks. Furthermore, the particle size is uniform. The reason is that when the temperature is close to the boiling point of acetone, the evaporation rate of the solvent is slow, which makes the fact that some of the solvents in the fog droplets do not evaporate immediately and particles agglomerate slowly. With the increase of temperature, the solvent in the droplet evaporates instantaneously to prevent the particles from adhering to each other. Thus, the optimum inlet temperature is chosen to be $80^{\circ} \mathrm{C}$.

3.1.3. Feed Suspension Flow Rate. It can be seen from Figure 4 that the particles obtained by spray-drying at different feed suspension flow rates $\left(1.5,4.5\right.$, and $\left.7.5 \mathrm{~mL} \cdot \mathrm{min}^{-1}\right)$ are all spherical in shape, but the surface coating effect is different. The samples obtained at $4.5 \mathrm{~mL} \cdot \mathrm{min}^{-1}$ are coated firmly with no shedding particles. This can be explained as the feed suspension flow rate affects the atomization velocity of droplets during spray-drying. The tiny droplets are more likely to be formed, and the drying process is quick at lower rates of the feed solution. Due to the explanation above, heat inside the particles transfers slowly, which makes samples have a rough surface. The atomization amount per unit time increases with the increase of feed solution. This caused the poor atomization effect. Thus, the optimum feed suspension flow rate is chosen as $4.5 \mathrm{~mL} \cdot \mathrm{min}^{-1}$.

3.2. SEM Characterization. The SEM images of recrystallized RDX and RDX/Al composites prepared by different methods are shown in Figure 5. From Figure 5(a), we can see that the morphology of recrystallized RDX is regular and the particle size is from 2 to $5 \mu \mathrm{m}$. As can be seen from Figure 5(b), the surface of RDX/Al composites prepared by the coveragemixing method is rough. And the particles adhere to each other, which makes dispersion of samples poor. The RDX/Al composites prepared by the spray-drying method are spherical with a smooth surface, and the particle size is about $100-200 \mu \mathrm{m}$ (see Figure 5(c)). And the particle size by the spray-drying method is larger than that of recrystallized RDX. Figure 5(d) shows that the particle is aggregated of many tiny granules, whose diameter ranges from $500 \mathrm{~nm}$ to $1 \mu \mathrm{m}$.

3.3. X-Ray Diffraction Characterization. The XRD analysis was carried out to investigate crystal types of raw RDX, recrystallized $\mathrm{RDX}, \mathrm{Al}$, and composites. The XRD patterns are shown in Figure 6. The diffraction angles of the recrystallized RDX were similar to the raw RDX, indicating that recrystallized RDX was generated without crystalline phase transformation. Furthermore, the diffraction peak of the recrystallized RDX was weakened compared with that of raw $\mathrm{RDX}$, due to the reduction of crystal size $[20,21]$. The XRD patterns of RDX/Al composites have characteristic peaks of both RDX and $\mathrm{Al}$, implying that the addition of $\mathrm{F}_{2602}$ and Al cannot affect the crystal type of RDX. And, compared to the recrystallized RDX, the diffraction peak intensity of the RDX/Al composites is much weaker. It is because $\mathrm{F}_{2602}$ and $\mathrm{Al}$ have amorphous characteristics [22].

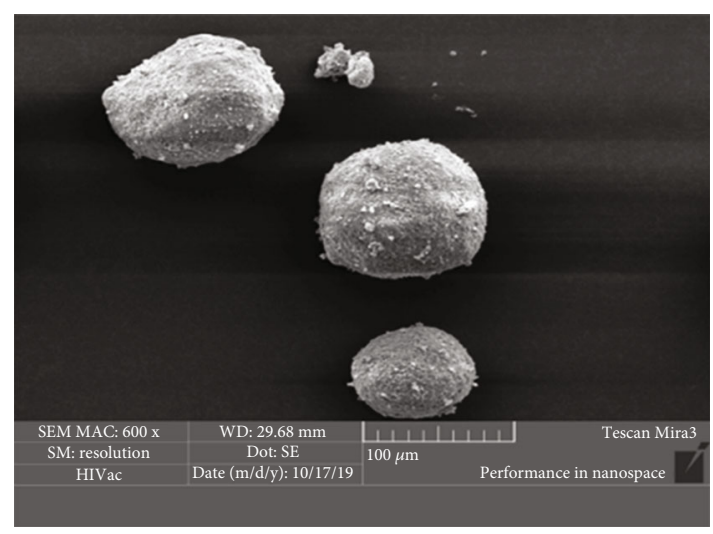

(a)

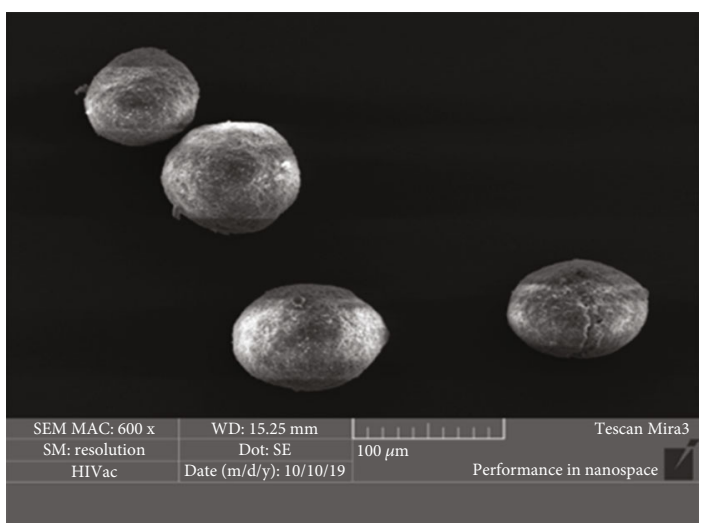

(b)

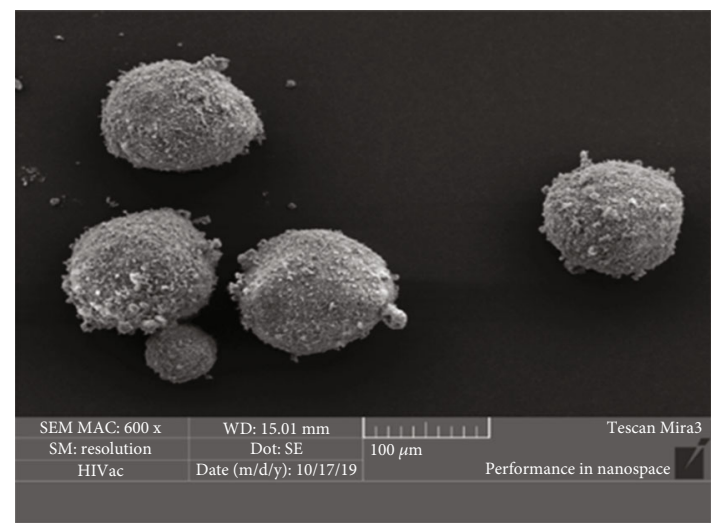

(c)

FIgURE 4: SEM images of samples under different feed suspension flow rates: (a) $1.5 \mathrm{~mL} \cdot \mathrm{min}^{-1}$, (b) $4.5 \mathrm{~mL} \cdot \mathrm{min}^{-1}$, and (c) $7.5 \mathrm{~mL} \cdot \mathrm{min}^{-1}$.

3.4. X-Ray Photoelectron Spectroscopy Characterization. The elemental content on the surface of recrystallized RDX and $\mathrm{RDX} / \mathrm{Al}$ composites prepared by different methods was analyzed by XPS, and the XPS spectra are presented in Figure 7. In addition, the mass fraction of the element in the sample surface is listed in Table 2.

As is shown in Figure 7 and Table 2, compared with the recrystallized $\mathrm{RDX}$, the content of $\mathrm{N}$ and $\mathrm{O}$ on the surface of $\mathrm{RDX} / \mathrm{Al}$ composites decreased, while the content of $\mathrm{C}$ increased. As $\mathrm{F}_{2602}$ does not contain $\mathrm{N}$ and $\mathrm{O}$, the content of $\mathrm{N}$ and $\mathrm{O}$ on the surface of the sample will decrease 


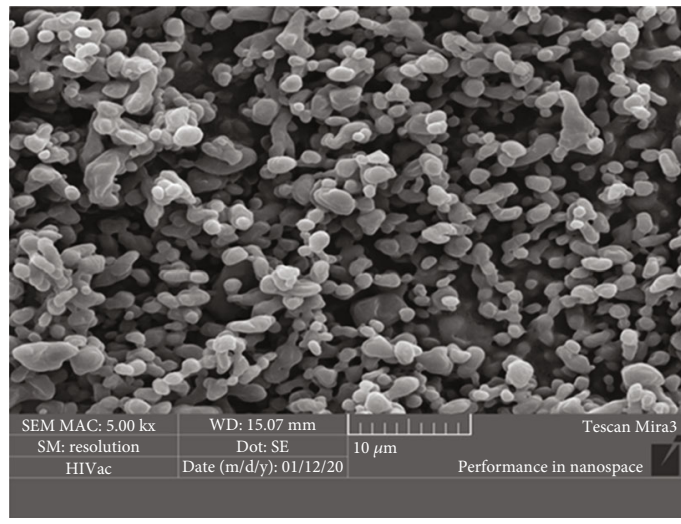

(a)

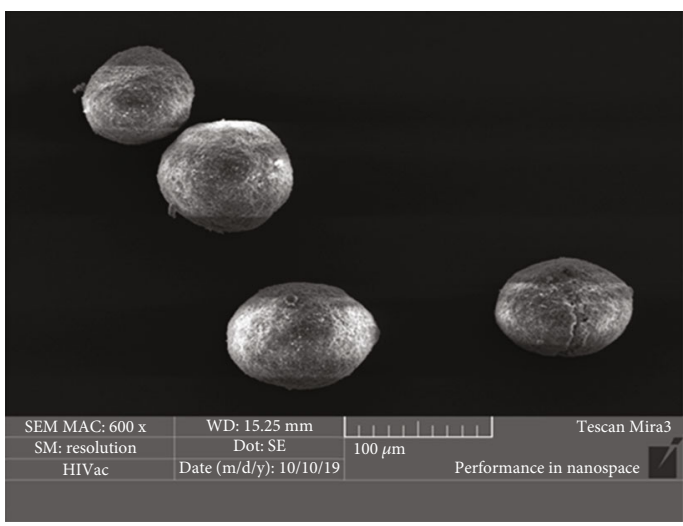

(c)

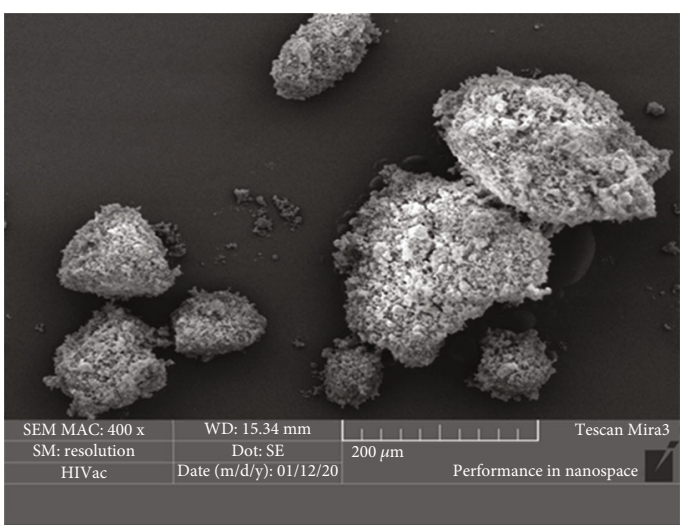

(b)

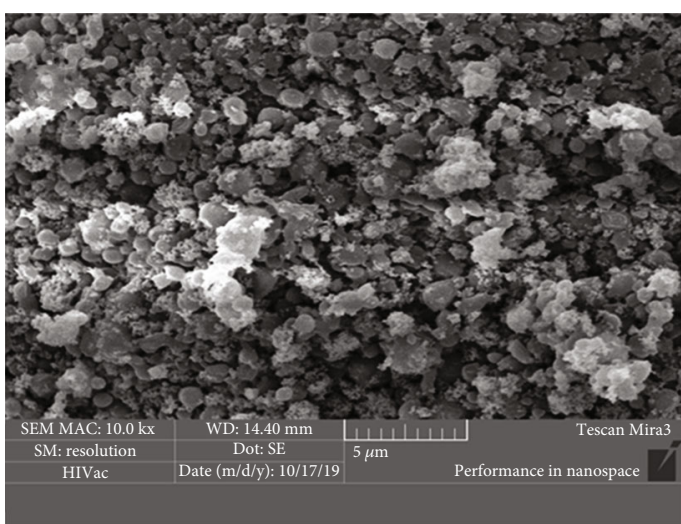

(d)

FIgURE 5: SEM images of (a) recrystallized RDX, (b) RDX/Al composites prepared by the coverage-mixing method, and (c, d) RDX/Al composites prepared by the spray-drying method.

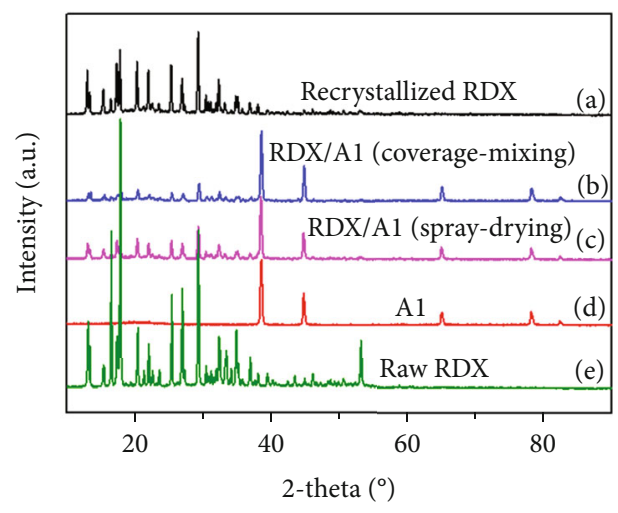

FIGURE 6: X-ray diffraction patterns of (a) recrystallized RDX, (b) $\mathrm{RDX} / \mathrm{Al}$ composites prepared by the coverage-mixing method, (c) $\mathrm{RDX} / \mathrm{Al}$ composites prepared by the spray-drying method, (d) $\mathrm{Al}$, and (e) raw RDX.

significantly [23]. The F content of the RDX/Al composites prepared by the spray-drying method is greater than that of $\mathrm{RDX} / \mathrm{Al}$ composites prepared by the coverage-mixing method, and the $\mathrm{Al}$ content is less. It can be explained by the different distribution of $\mathrm{F}_{2602} . \mathrm{F}_{2602}$ is coated on the surface of the sample prepared by the spray-drying method, while the distribution of $\mathrm{F}_{2602}$ in the sample prepared by the coverage-mixing method is disordered.

3.5. Thermal Decomposition Characterization. To investigate the effect of the preparation method on thermal decomposition of samples, the recrystallized RDX and RDX/Al composites prepared by different methods were analyzed by DSC. The DSC curves are shown in Figure 8.

As can be seen from Figure 8, there is an obvious relationship between the decomposition peak temperature and the heating rate. That is, the decomposition peak temperature of samples rises with the increase of the heating rate. According to Figure 8, the decomposition peak temperature of $\mathrm{RDX} / \mathrm{Al}$ composites prepared by the coveragemixing method and spray-drying method is lower than that of recrystallized RDX, which can be attributed to the high thermal conductivity of $\mathrm{Al}$ : the addition of $\mathrm{Al}$ in the samples can accelerate the thermal decomposition of RDX [24].

The thermal decomposition kinetic parameters of samples were evaluated by the Kissinger equation [25] (1)-(3), and the calculated results are shown in Table 3:

$$
\ln \left(\frac{\beta_{i}}{T_{p i}^{2}}\right)=\ln \left(\frac{A R}{E_{\mathrm{a}}}\right)-\frac{E_{\mathrm{a}}}{R T_{p i}},
$$




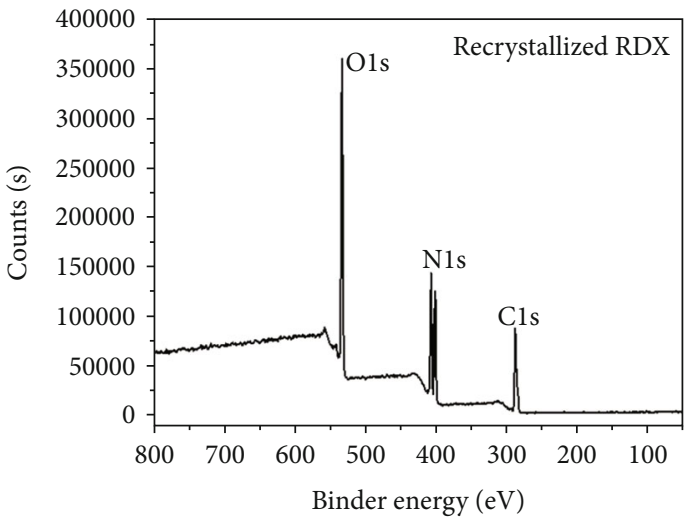

(a)

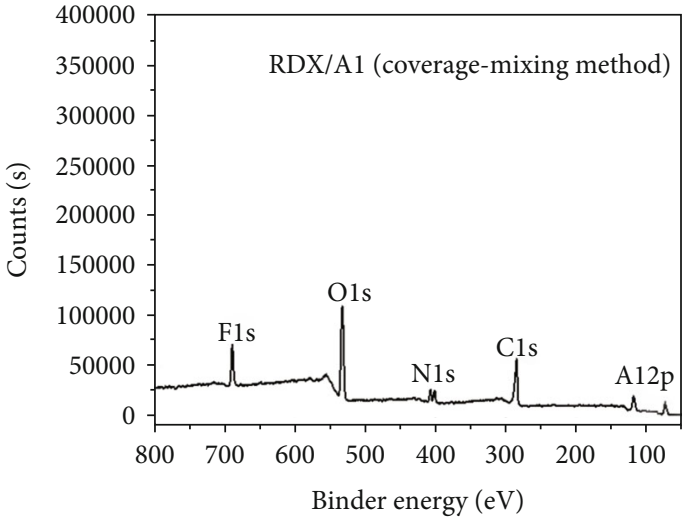

(b)

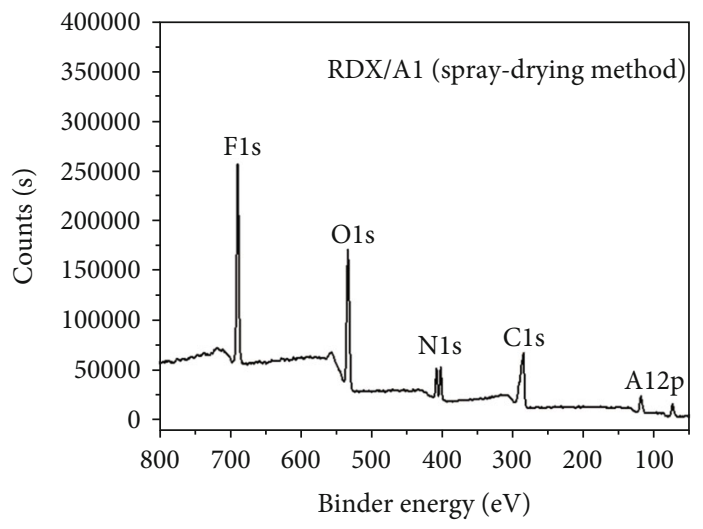

(c)

FIGURE 7: XPS spectrum of recrystallized RDX and RDX/Al composites prepared by different methods.

TABLE 2: Distribution of elements on the surface of samples.

\begin{tabular}{lccccc}
\hline \multirow{2}{*}{ Sample } & \multicolumn{5}{c}{ Surface elements (\%) } \\
& C1s & N1s & O1s & F1s & Al2p \\
\hline Recrystallized RDX & 32.84 & 24.53 & 42.63 & & \\
RDX/Al (coverage-mixing) & 39.98 & 5.71 & 29.97 & 10.17 & 14.17 \\
RDX/Al (spray-drying) & 38.57 & 7.01 & 24.41 & 21.69 & 8.32 \\
\hline
\end{tabular}

$$
\begin{aligned}
& T_{p i}=T_{p 0}+b \beta_{i}+c \beta_{i}^{2}, \\
& T_{b}=\frac{E-\sqrt{E^{2}-4 R E T_{p 0}}}{2 R},
\end{aligned}
$$

where $\beta_{i}$ is the heating rate (in Kelvins per min), $T_{p i}$ is the exothermic peak temperature in the DSC curve (in Kelvins), $A$ is the preexponential factor, $R$ is the gas constant $\left(8.314 \mathrm{~J} \cdot \mathrm{mol}^{-1} \cdot \mathrm{K}^{-1}\right), E_{\mathrm{a}}$ is the apparent activation energy (in $\mathrm{J} \cdot \mathrm{mol}^{-1}$ ), $T_{p 0}$ is the peak temperature when $\beta_{i}$ is zero (in Kelvins), and $T_{b}$ is the critical explosion temperature (in Kelvins).

It can be found from Table 3 that the apparent activation energy $\left(E_{\mathrm{a}}\right)$ of the recrystallized RDX and RDX/Al composites prepared by the coverage-mixing method and spray-drying method is $127.54,125.32$, and $126.63 \mathrm{~kJ} \cdot \mathrm{mol}^{-1}$.
Compared with the recrystallized RDX, $E_{\mathrm{a}}$ of the RDX/Al composites reduce by 2.22 and $0.91 \mathrm{~kJ} \cdot \mathrm{mol}^{-1}$, respectively. It indicates that $\mathrm{Al}$ reduces the apparent activation energy of the RDX and has an obvious catalytic effect on the thermal decomposition of the RDX [24]. It can also be seen from Table 3 that $E_{\mathrm{a}}$ and $T_{b}$ of the RDX/Al composites prepared by the spray-drying method are higher than that of the RDX/Al composites prepared by the coverage-mixing method. It shows that the thermal stability of the RDX/Al composites prepared by the spray-drying method is better than that of the $\mathrm{RDX} / \mathrm{Al}$ composites prepared by the coverage-mixing method.

3.6. Impact Sensitivity Characterization. The mechanical sensitivity of recrystallized RDX and RDX/Al composites was tested, and the results are shown in Table 4.

From Table 4, it can be found that the drop height $\left(\mathrm{H}_{50}\right)$ of recrystallized RDX is $38.6 \mathrm{~cm}$. After adding $\mathrm{Al}$, the impact sensitivity of the RDX/Al composites is significantly reduced than that of the recrystallized RDX, suggesting that the addition of $\mathrm{Al}$ reduces the impact sensitivity of the RDX. Because of the high thermal conductivity of $\mathrm{Al}$, the heat generated by the impact and friction stimulus on the RDX surface can be dispersed in time so as to prevent the formation of hot spots [26]. Additionally, compared to the RDX/Al composites prepared by the coverage-mixing method, $H_{50}$ of the RDX/Al composites prepared by the spray-drying 


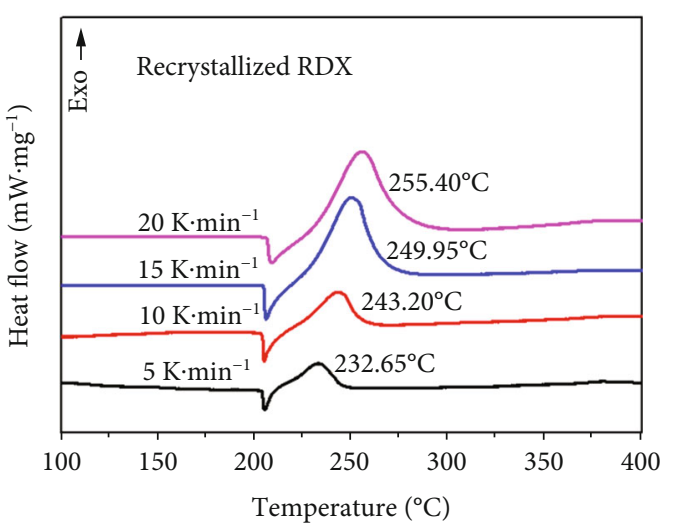

(a)

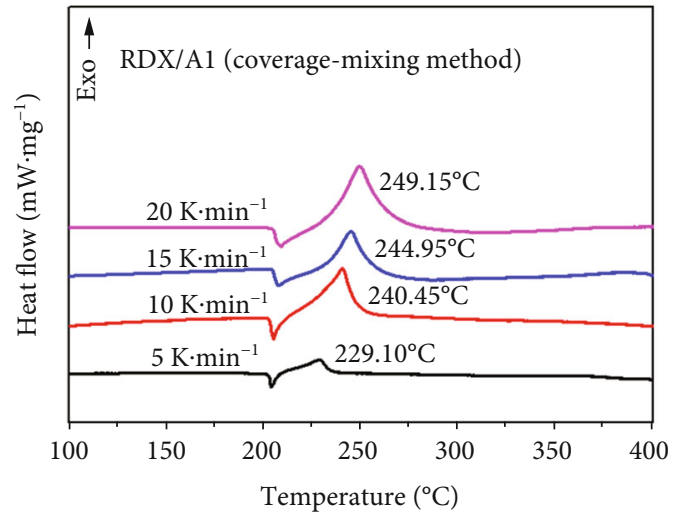

(b)

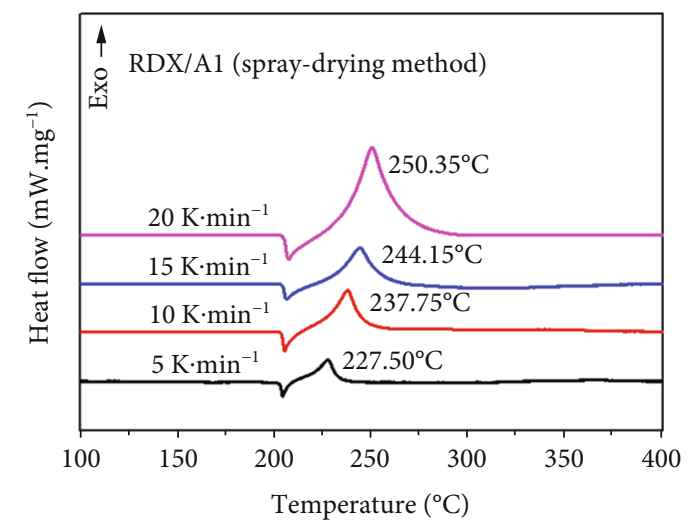

(c)

FIGURE 8: DSC curves of recrystallized RDX and RDX/Al composites prepared by different methods.

TABLE 3: The thermal decomposition kinetic parameters of samples.

\begin{tabular}{|c|c|c|c|c|}
\hline Sample & $E_{\mathrm{a}}\left(\mathrm{kJ} \cdot \mathrm{mol}^{-1}\right)$ & $\ln A$ & $T_{p 0}(\mathrm{~K})$ & $T_{b}(\mathrm{~K})$ \\
\hline Recrystallized RDX & 127.54 & 22.23 & 488.95 & 505.19 \\
\hline RDX/Al (coverage-mixing) & 125.32 & 22.02 & 482.90 & 499.02 \\
\hline RDX/Al (spray-drying) & 126.63 & 22.24 & 484.60 & 500.66 \\
\hline
\end{tabular}

TABLE 4: Impact sensitivity of recrystallized RDX and RDX/Al composites.

\begin{tabular}{lcc}
\hline Sample & Contents (wt.\%) & $\begin{array}{c}\text { Impact sensitivity } \\
H_{50}(\mathrm{~cm})\end{array}$ \\
\hline Recrystallized RDX & $\mathrm{RDX}(100 \%)$ & 38.6 \\
RDX/Al (coverage-mixing) & $\begin{array}{c}\mathrm{RDX} / \mathrm{Al} / \mathrm{F}_{2602} \\
(63 / 35 / 2)\end{array}$ & 99.5 \\
$\mathrm{RDX} / \mathrm{Al}$ (spray-drying) & $\begin{array}{c}\mathrm{RDX} / \mathrm{Al} / \mathrm{F}_{2602} \\
(63 / 35 / 2)\end{array}$ & 106.9 \\
\hline
\end{tabular}

method is increased by $7.4 \mathrm{~cm}$. Since the RDX/Al composites were prepared by the spray-drying method, $\mathrm{Al}$ is evenly dispersed. On account of the good thermal conductivity of $\mathrm{Al}$, the heat generated by impact and friction stimulus of the composites cannot be concentrated effectively, thus reducing the probability of hot spot formation. It can be concluded that the RDX/Al composites prepared by the spray-drying method have lower mechanical sensitivity.

\section{Conclusion}

$\mathrm{RDX} / \mathrm{Al}$ composites have been prepared successfully by the spray-drying method with $\mathrm{F}_{2602}$ as a binder. The spraydrying process parameters were found to affect the morphology and dispersion of the samples. Optimal morphology of samples was achieved when the inlet temperature, nitrogen flow rate, and suspension feed flow rates were $80^{\circ} \mathrm{C}$, $473 \mathrm{~L} \cdot \mathrm{h}^{-1}$, and $4.5 \mathrm{~mL} \cdot \mathrm{min}^{-1}$, respectively. The morphology of $\mathrm{RDX} / \mathrm{Al}$ composites was spherical, and the particle distribution was homogenous. The performance tests reveal that the addition of nAl could accelerate the thermal decomposition of the RDX. Compared with the RDX/Al composites prepared by the coverage-mixing method, the RDX/Al composites prepared by the spray-drying method have better 
thermal stability and lower impact sensitivity. In conclusion, these combined properties indicate that the RDX/Al composites prepared by the spray-drying method have better security performance.

\section{Data Availability}

The data used to support the findings of this study are available from the corresponding author upon request.

\section{Conflicts of Interest}

The authors declare that there is no conflict of interest regarding the publication of this paper.

\section{References}

[1] A. S. Kumar, V. B. Rao, and R. K. Sinha, "Evaluation of plastic bonded explosive (PBX) formulations based on RDX, aluminum, and HTPB for underwater applications," Propellants Explosives Pyrotechnics, vol. 35, no. 4, pp. 359-364, 2010.

[2] P. P. Vadhe, R. B. Pawar, and R. K. Sinha, "Cast aluminized explosives (review)," Combustion Explosion \& Shock Waves, vol. 44, no. 4, pp. 461-477, 2008.

[3] X. H. Li, H. B. Pei, and X. Zhang, "Effect of aluminum particle size on the performance of aluminized explosives," Propellants Explosives Pyrotechnics, vol. 45, no. 5, pp. 807-813, 2020.

[4] A. N. Zhigach, I. O. Leipunskii, and N. G. Berezkina, "Aluminized nitramine-based nanocomposites: manufacturing technique and structure study," Combustion Explosion \& Shock Waves, vol. 45, no. 6, pp. 666-677, 2009.

[5] X. X. Mao, Y. C. Li, and Y. F. Li, "Thermal properties of decomposition and explosion for CL-20 and CL-20/n-Al," Journal of Energetic Materials, vol. 38, no. 1, pp. 98-110, 2019.

[6] H. Huang, Y. Huang, and S. B. Li, "Research on composite explosive with nano-aluminium," Chinese Journal of Explosivese Propellants, vol. 25, no. 2, pp. 1-3, 2002.

[7] F. Shen, H. Wang, and J. F. Yuan, "Influence of Al content on the driving ability of RDX-based aluminized explosives," Chinese Journal of Explosives \& Propellants, vol. 36, no. 3, pp. 5053, 2013.

[8] S. P. Wang, X. F. Feng, and L. N. Yao, "The influence of nanometer aluminum on the explosion heat of RDX-based explosive," Initiators \& Pyrotechnics, no. 1, pp. 21-24, 2014.

[9] L. N. Yao, X. S. Feng, and S. X. Zhao, "Influence of nano Al on mechanical sensitivity and flame sensitivity of RDX-based explosive," Chinese Journal of Explosives \& Propellants, vol. 35, no. 4, pp. 15-18, 2012.

[10] X. S. Feng, X. J. Feng, and J. Zhao, "Effect of content and particle size of aluminum powder on the air blast property of HMX-based explosive," Explosive Materials, vol. 47, no. 4, pp. 10-15, 2018.

[11] W. Zhang, J. L. Zhang, and J. Y. Wang, "Preparation of $\mathrm{RDX} / \mathrm{Fe} 2 \mathrm{O} 3-\mathrm{Al} 2 \mathrm{O} 3$ nano-composite energetic material by sel-gel," Guangdong Chemical Industry, vol. 41, no. 7, 2014.

[12] Y. B. Sun, J. M. Hui, and M. Y. Cao, Military Composite Explosive, Tianjin: Arms Industry Press, 1995.

[13] C. L. Nie, D. Y. Ren, and X. F. Wang, "Simulation and experimental study on flow behavior of simulant explosive composites during twin-screw extrusion," Chinese Journal of Explosives \& Propellants, vol. 37, no. 5, pp. 85-90, 2014.
[14] X. Miao, H. X. Xu, and X. P. Zhao, "Safety of nano-Al/RDX mixtures," Chinese Journal of Explosives \& Propellants, vol. 38, no. 5, pp. 69-73, 2015.

[15] W. Ji, X. D. Li, and J. Y. Wang, "Effect of the spray drying technological conditions on the particle size of $\mathrm{HMX} / \mathrm{F}_{2602}$ coreshell composite microspheres," Chinese Journal of Energetic Materials, vol. 24, no. 3, pp. 295-299, 2016.

[16] W. Z. Xu, J. Wang, and J. Y. Peng, "Study on the influencing factors of ultrafine spherical RDX during spray drying with low speed," Journal of Nanomaterials, vol. 2019, Article ID 7915129, 10 pages, 2019.

[17] Y. P. Zhang, C. H. Hou, and X. L. Jia, "Fabrication of nanoparticle-stacked 1, 1-diamino-2, 2-dinitroethylene (FOX-7) microspheres with increased thermal stability," vol. 2019, Article ID 2981796, 9 pages, 2019.

[18] A. N. Zhigach, I. O. Leipunskii, and A. N. Pivkina, "Aluminum/HMX nanocomposites: synthesis, microstructure, and combustion," Combustion Explosion \& Shock Waves, vol. 51, no. 1, pp. 100-106, 2015.

[19] National Military Standard of China, "Experimental methods of sensitivity and safety," 1997, GJB/772 A-97.

[20] X. F. Shi, J. Y. Wang, and X. D. Li, "Preparation and characterization of HMX/Estane nanocomposites," Central European Journal of Energetic Materials, vol. 11, no. 3, pp. 433-442, 2014.

[21] G. C. Yang, F. D. Nie, and H. Huang, "Preparation and characterization of nano-TATB explosive," Propellants, Explosives, Pyrotechnics, vol. 31, no. 5, pp. 390-394, 2006.

[22] X. L. Jia, C. H. Hou, and Y. X. Tan, "Fabrication and characterization of PMMA/HMX-based microcapsules via in situ polymerization," Central European Journal of Energetic Materials, vol. 14, no. 3, pp. 559-572, 2017.

[23] Y. B. Li, H. J. Huang, and H. Huang, "Desensitizing technology of high quality HMX by coating," Chinese Journal of Energetic Materials, vol. 20, no. 6, pp. 680-684, 2012.

[24] L. Liang, J. Y. Wang, and J. Dong, "Effects of nano-Al powder on the thermal decomposition catalytic performance of nitroamine explosives," Chinese Journal of Explosives \& Propellants, vol. 32, no. 6, pp. 75-78, 2009.

[25] H. E. Kissinger, "Reaction kinetics in differential thermal analysis," Analytical Chemistry, vol. 29, no. 11, pp. 1702-1706, 1957.

[26] A. M. Mellor, D. A. Wiegand, and K. B. Isom, "Hot spot histories in energetic materials," Combustion and Flame, vol. 101, no. 1-2, pp. 26-35, 1995. 